\title{
SPECIAL ASPECTS OF THE EFFICIENT DAILY ROUTINE OF STUDENTS AT MODERN EDUCATIONAL ESTABLISHMENTS OF DIFFERENT TYPES
}

DOI: 10.36740/WLek202007138

\author{
Oksana V. Tymoshchuk, Oksana Y. Zhurakivska, Volodymyr V. Derpak, Iryna 0. Kostitska, Iryna T. Tokar \\ THE STATE HIGHER EDUCATIONAL INSTITUTION «IVANO FRANKIVSK NATIONAL MEDICAL UNIVERSITY», IVANO-FRANKIVSK, UKRAINE
}

\begin{abstract}
The aim of study is special aspects of the efficient daily routine of students at modern educational institutions of different types, and its influence on psychophysical functions, adaptive abilities, the quality of life as well as the state of mental and somatic health of the youngsters.

Materials and methods: While studying special aspects of the daily routine of students at modern educational institutions and their influence on the state of physical and mental health, the young people were observed in five modern educational establishments in Ivano-Frankivsk:Vasyl Stefanyk Precarpathian National University, Ivano-Frankivsk Finance Commercial Cooperative College named after S.Granat, Ivano-Frankivsk music school named after Denis Sichinskiy, Ivano-Frankivsk Vocational Motor Transport and Construction Lyceum № 15, Ivano-Frankivsk boarding lyceum for gifted young people from rural areas. 300 students were observed (150 female students and 150 male students). The study analyzed their educational conditions, daily routine tension, and activities during breaks, special aspects of leisure arrangements, amount of time spent on homework, subjective assessment of the level of tension of the educational process, and their projected influence on the health state of students by using static models.

Results: Received results of the assessment of sanitary and hygienic conditions under which training takes place at modern educational institutions of different types, as well as conditions of after school activities of the students, by applying common methods to evaluate illumination level, microclimate, and air quality have revealed that the youngsters' conditions at modern educational institutions are marked by absence of significant deviations from common hygienic requirements, they are similar and easily comparable and that enables defensibly and illuminatively to identify main features of influence of the different psychohygienic methods on the development of health maintaining tools and the establishment of features of the formation of functional capabilities and the basic correlates of mental and physical health.

Conclusions: The educational conditions of young people in modern educational establishments can be described as not having considerable deviations from common hygienic requirements, being easily comparable and enabling to identify main influence factors of different types of psychohygienic methods of developing and implementing of healthmaintaining tools on the course of formation of the functional capabilities of the body and the development of the main adaptation reactions in young males and females.
\end{abstract}

KEY WORDS: daily routine, educational process, educational institutions, students, health status

\section{INTRODUCTION}

According to the data of the World Health Organization, health assessment of the Ukrainian population in the present-day conditions appears to be not merely a medical issue but a complex matter. The formation of health culture guarantees self-fulfillment of the youth, providing active leisure, possibilities to start a family, fulfillment of hard training and work, social and political activities. Young people in the modern society often make health their first priority but spare no effort to maintain and improve it. Therefore, we should pay a great attention to teaching methods of promoting healthy lifestyle behaviors among students and building health value. Need for health has to become a standard of human life. While analyzing scientific resources, two main notions stand out: "culture" and "health". The notion "culture" covers science, education, ethics and life style [1-3]. "Health" is affected by the factors, which could be split into 2 groups. The first group includes factual characteristics of the educational process: duration of the school day, study load, activities during the breaks, microclimate in rooms. The second group consists of subjective personal characteristics: diet, sport and morning exercises, hardening, leisure activities, and bad habits. Under real conditions, just the second group of factors really influences the health of young people. Therefore, we should constantly promote ideas of healthy lifestyle, develop skills of healthy lifestyle, and engage into establishment of principles of healthy lifestyle. Health of a person mainly depends on their lifestyle, working conditions, physical activity, leisure aspects, diet and habits.

Daily routine and leisure time are significant for recovery. Daily routine is an assigned order, duration and alteration of work and rest during a day, as well as diet, sport, morning exercises, sleep, observing rules of personal hygiene. It is a general pace of life and activities of students, which takes into consideration biological rhythms, as well as special aspects of physical and mental load. Regular change of the routine elements sets certain rhythm of body processes and creates a reflex, which can last for some time. A daily routine facilitates setting of certain biological rhythms of a body. $[4,5]$. 
A certain duration of physical or mental work, an alteration of different activities, a balanced diet, a necessary duration of the night sleep, regular morning exercises and enough movement provide conditions to improve working efficiency and successful personal development of students

The main feature of the healthy lifestyle of students at modern educational establishments of different types is an efficient daily routine, which includes well-organized studying, a healthy diet, physical activity, morning exercises, body strengthening procedures and absence of bad habits. The basic objective of the efficient daily routine is to create condition for efficient physical and mental work of students and the most comfortable functioning of all body systems. The fundamental regulation tool is alteration of different activities during a day.

\section{THE AIM}

The study aims is special aspects of the efficient daily routine of students at modern educational institutions of different types, and its influence on psychophysical functions, adaptive abilities, the quality of life as well as the state of mental and somatic health of the youngsters.

\section{MATERIALS AND METHODS}

While studying special aspects of the daily routine of students at modern educational institutions and their influence on the state of physical and mental health, the young people were observed in five modern educational establishments in Ivano-Frankivsk: Vasyl Stefanyk Precarpathian National University, Ivano-Frankivsk Finance Commercial Cooperative College named after S.Granat, Ivano-Frankivsk music school named after Denis Sichinskiy, Ivano-Frankivsk Vocational Motor Transport and Construction Lyceum No 15, Ivano-Frankivsk boarding lyceum for gifted young people from rural areas. 300 students were observed (150 female students and 150 male students). The study analyzed their educational conditions, daily routine tension, and activities during breaks, special aspects of leisure arrangements, amount of time spent on homework, subjective assessment of the level of tension of the educational process, and their projected influence on the health state of students by using static models.

The selection of objects for observation, their grouping and classification according to the main indicators was performed considering the quantitative and qualitative representativeness of the research. The number of subjects surveyed in each group was estimated using mathematical formulas that determined the minimum amount of statistical sample and obtaining reliable results in accordance with the objectives and determined the quantitative representativeness of the research results, which guarantees the validity of the work.

In order to achieve the homogeneity of the studied groups and to ensure the necessary level of qualitative representativeness of the work, there were taken into consideration gender and age of the surveyed, psychological and pedagogical conditions of the educational environment, as well as examining of the conditions of training and after school activities, duration of homework, activity during breaks, participation in sports sections, morning exercises and qualitative and quantitative indicators of the influence of the factors of the educational environment on the somatic health of young males and females. As part of the research process new modern highly informative hygiene, medical and sociological, epidemiological, psychological, physiological, psychodiagnostic and methods of multivariate statistical analysis and forecasting with strict observance of phasedness and sequence of their conduct were used. There was carried out a sanitary-hygienic assessment of the regime of the day and independent work, as well as studied the intensity of training, activity at a break, the way morning exercises are done, sports, recreation, housing and living conditions and the conditions of the educational environment of boys and girls.

Required data was obtained from specially designed questionnaires and interviews, also there was carried out hygienic assessment of the main components of the daily routine of students, and their health was examined too. The main characteristics of correlation between the state of health and the conditions in educational institutions, living and social conditions of life outside school, the daily routine and leisure, sports, strengthening, activity during breaks, intensity of the educational process of boys and girls were determined by methods of descriptive statistics and correlation analysis.

The statistical processing of the results of the study was carried out using programs of multivariate statistical analysis "Statistica 5.5 for Windows" (owned by the Center of new Information Technologies of the Vinnitsa National Medical University named after M.I. Pirogov, license No AXX910A374605FA) and "Statistica 6.0 for Windows" (ownership of the Center of new Information Technologies of the Vinnitsa National Medical University named after M.I. Pirogov, license \#BXXR901E245722FA). An important role in the statistical processing of the obtained results obtained belonged to the methods of descriptive statistics of data that characterized the formation and dynamic changes of the studied characteristics and were used to determine the arithmetic mean values $(M)$, standard deviations (s) and standard errors of average values $(\mathrm{m})$. The degree of validity of the data was carried out using parametric (calculation of the Student's criterion $(\mathrm{t})$ ) and non-parametric parameters (Pearson's (P2) and Wilcoxon criteria (W)), and their results were evaluated according to the significance level (p). For an in-depth, practically-significant statistical evaluation of the comparison groups, the method of comparing the frequencies of the binary trail was used in two unrelated groups using a method of analysis of tables $2 \times 2$. To assess the course of adaptation processes and predict their impact on the health of students correlation, cluster and factor analysis were applied.

\section{RESULTS AND DISCUSSION}

Received results of the assessment of sanitary and hygienic conditions under which training takes place at modern ed- 

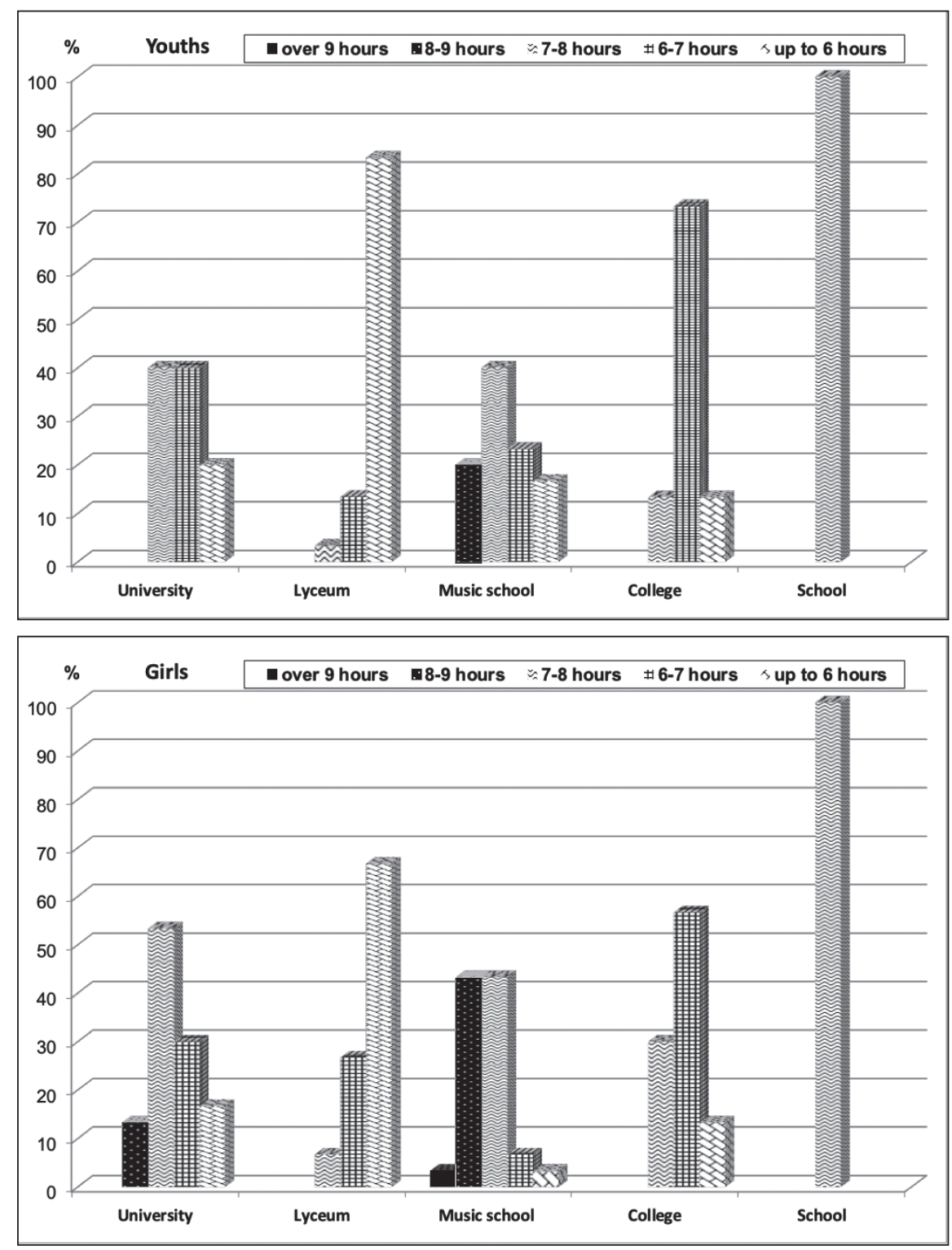

Fig. 1. Duration of stay in an educational institution, young male
Fig. 2. Duration of stay in an educational institution, young female ucational institutions of different types, as well as conditions of after school activities of the students, by applying common methods to evaluate illumination level, microclimate, and air quality have revealed that the youngsters' conditions at modern educational institutions are marked by absence of significant deviations from common hygienic requirements, they are similar and easily comparable and that enables defensibly and illuminatively to identify main features of influence of the different psychohygienic methods on the development of health maintaining tools and the establishment of features of the formation of functional capabilities and the basic correlates of mental and physical health. [6].

While analyzing the time students spent in educational establishments, it should be emphasized that only 3.3\% of girls in the college had more than 9 hours of training activity. Between 8 and 9 hours, this figure described 30.0\% of boys and $13.3 \%$ of girls in the college and $43.3 \%$ of boys and $20.0 \%$ of girls in the music school.

Between 7 and 8 hours were spent by $53.3 \%$ of boys and $40.0 \%$ of girls at university, $73.3 \%$ of boys and $56.7 \%$ of girls at the college, $40.0 \%$ of boys and $43.3 \%$ girls of the music school, $3,3 \%$ of boys and $6.7 \%$ of girls in the lyceum, as well as $100.0 \%$ of boys and $100.0 \%$ of girls in the school respectively. The duration from 6 to 7 hours was for $40.0 \%$ of boys and $30.0 \%$ of girls of the university, $13.3 \%$ of boys and $13.3 \%$ of the college girls, $23.3 \%$ of boys and $6.7 \%$ girls of the music school and $13.3 \%$ of boys and $26.7 \%$ of girls in lyceum. Up to 6 hours - for 20,0\% of boys and 16,7\% of girls of the university, $16,7 \%$ of boys and $3,3 \%$ girls of the school and $83,3 \%$ of boys and $66,7 \%$ of girls of lyceum (Fig. 1, Fig. 2).

The obtained results revealed the existence of clearly expressed signs of a significant excess of sanitary and hygiene requirements for the duration of daytime stay of students in various modern educational institutions, which has a significant negative impact on the level of functional and psychological capabilities of the body of students [7-9]. Indicators of the time students spent on homework assignments and the projects provided by the curriculum, on self-study assignments and home reading 

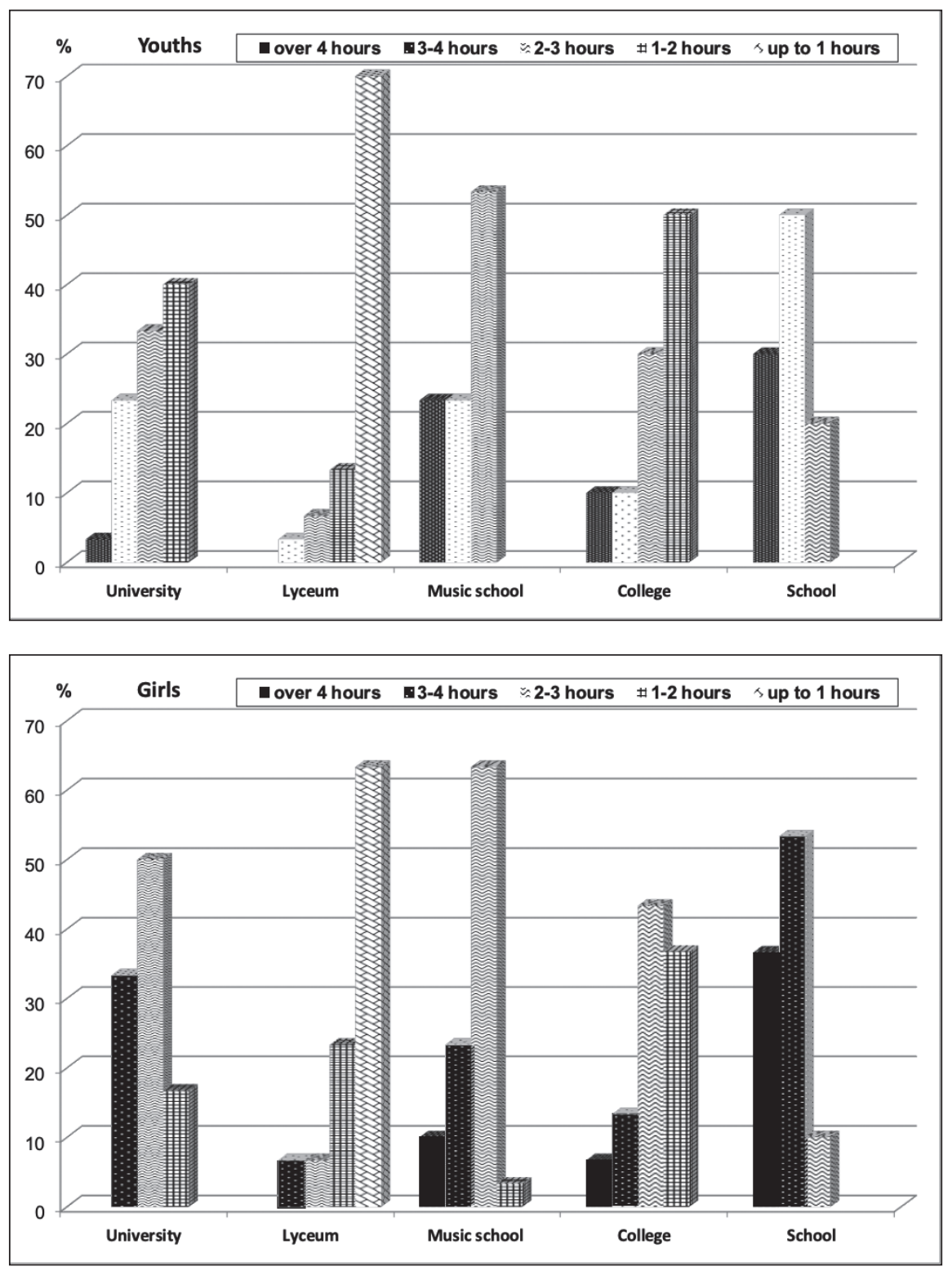

Fig. 3. Time spent on homework, young male

Fig. 4. Time spent on homework, young female described the following time distribution (Fig. 3, Fig. 4). More than 4 hours on these activities were spent by $3.3 \%$ of university students, $10.0 \%$ of boys and $6.7 \%$ of college girls, $23.3 \%$ of boys and $10.0 \%$ of girls of music school, as well as $30.0 \%$ of boys and $36,7 \%$ of girls in school. From 3 to 4 hours $-23.3 \%$ of boys and $33.3 \%$ of university girls, $10.0 \%$ of boys and $13.3 \%$ of college girls, $23.3 \%$ of boys and $23.3 \%$ of girls of the musical school, $3.3 \%$ of boys and $6.7 \%$ of girls in the lyceum, as well as $50.0 \%$ of boys and $53.3 \%$ of girls in the school. From 2 to 3 hours, respectively, $33.3 \%$ of boys and $50.0 \%$ of university girls, $30.0 \%$ of boys and $43.3 \%$ of college girls, $53.3 \%$ of boys and $63.3 \%$ girls of the music school, $6.7 \%$ of boys and $6.7 \%$ girls in the lyceum, as well as $20.0 \%$ of boys and $10.0 \%$ of girls in the school. From 1 to 2 hours $-40.0 \%$ of boys and $16.7 \%$ of university girls, $50.0 \%$ of boys and $36.7 \%$ of college girls, $3.3 \%$ girls of the music school and $13.3 \%$ of boys and $23.3 \%$ of girls in the lyceum. Only students of the lyceum spent up to 1 hour on homework $-76.7 \%$ of boys and $63.3 \%$ of girls respectively.
While analyzing the scheduled breaks and studying the way they are arranged, it was established that they are organized in these educational institutions as standard, and students spend time during such breaks mostly passively. According to the results, passive leisure during breaks was typical for $86.7 \%$ of boys and $63.3 \%$ of girls of the university, $76.7 \%$ of boys and $46.7 \%$ of college girls, $76.7 \%$ of boys and $67,7 \%$ of girls at the music school, $80.0 \%$ boys and $70.0 \%$ girls of the lyceum, as well as $76.7 \%$ of boys and $33.3 \%$ of girls of the school. In general, during the scheduled breaks the following proportions of students were preparing for the following lessons: respectively $6.7 \%$ of boys and $20.0 \%$ of girls of the university, $16.7 \%$ of boys and $43.3 \%$ of college girls, $20.0 \%$ of boys and $20.0 \%$ of girls at the music school, $10.0 \%$ of boys and $3.3 \%$ of girls in the lyceum, as well as $20.0 \%$ of boys and $56.7 \%$ of girls in the school. Active forms of rest during breaks were characteristic of $6.7 \%$ of boys and $16.7 \%$ of university girls, $6.7 \%$ of boys and $10.0 \%$ of college girls, $3.3 \%$ of boys and $13.3 \%$ of girls of the music school, $10.0 \%$ of boys and $26.7 \%$ of girls in the lyceum, as well as $3.3 \%$ of boys and $10.0 \%$ of girls in the school. Most of the students in their free 
time were watching television, that is $53.3 \%$ of boys and $50.0 \%$ of girls at the university, $73.3 \%$ of boys and $40.0 \%$ of college girls, $80.0 \%$ of boys and $50.0 \%$ girls of the music school, $53.3 \%$ of boys and $50.0 \%$ of girls of lyceum, as well as $73.3 \%$ of boys and $40.0 \%$ of girls of the school. Non-educational institutions were attended by $13.3 \%$ of boys and $20.0 \%$ of university girls, $6.7 \%$ of boys and $33.3 \%$ of college girls, $3.3 \%$ of boys and $10.0 \%$ of girls of the music school, $13.3 \% \%$ of boys and $20.0 \%$ of girls in the lyceum, as well as $6.7 \%$ of boys and $33.3 \%$ of girls in the school. $3.3 \%$ of boys and $3.3 \%$ of university girls, $6.7 \%$ of boys and $3.3 \%$ of college girls, $10.0 \%$ of boys and $23.3 \%$ girls of the music school, 3,3\% of boys and 3.3\% of girls in the lyceum, as well as 3.3\% of boys and 3.3\% of girls in the school work in their degree field or have other part-time jobs.

The prospects for further research can be in the further comprehensive study of the peculiarities of the daily routine of students at modern educational institutions of different types, the assessment of the impact of the daily routine on adaptive capacity, quality of life and the state of physical and mental health of boys and girls.

\section{CONCLUSIONS}

1. The educational conditions of young people in modern educational establishments can be described as not having considerable deviations from common hygienic requirements, being easily comparable and enabling to identify main influence factors of different types of psychohygienic methods of developing and implementing of health-maintaining tools on the course of formation of the functional capabilities of the body and the development of the main adaptation reactions in young males and females.

2. Indicators of the assessment of the characteristics of the basic social and household characteristics of the organization of life and the educational environment of students show the existence of favorable housing, living conditions and conditions of permanent residence in the vast majority.

3. While assessing the daily routine of students at modern educational institutions, special attention should be paid to the significant deviations found in the organization of the main aspects of training and after school activities from the generally accepted sanitary and hygienic standards. First of all, this regards the substantial excess of the maximum permissible duration of the daytime stay of students in the training as well as the length of time that was required for practical training and homework outside the educational institution.

\section{REFERENCES}

1. Vlasov G.V. Formation of a healthy way of life for students of higher medical educational institutions. Vestnik of Hygiene and Epidemiology. 2013; 5: 121-133.

2. Sergeta I.V., Alexandrova 0.Y., Stoyan N.V., Dunets I.L. Influence of the conditions of stay in a higher educational institution on the processes of forming the peculiarities of the student's personality and the problems of psychohygienic correction of the detected shifts. Materials of the III interregional scientific-practical conference. Vinnytsia. 2011; 10: 101-117.
3. Chekalova S.A., Chekalova N.G. Condition of neuropsychiatric health of adolescents and ways of its correction. Acute questions of psychohygiene and protection of mental health of children and adolescents. 2007; 3: 252-253.

4. Vorontsov M.P., Korobchansky V.0., Mikheev V.V. Psychohygienic optimization of adaptive-compensatory reactions at the stage of prenosological conditions in adolescent pupils. The health of schoolchildren at the turn of the millennium. Kharkiv. 2000; 96-115.

5. Korobchansky V.A., Vrystychak S.V. Hygienic prenosological psychodiagnostics: methodological bases and practical perspectives. Environment and health. 2005; 4 (35): 9-14.

6. Skorokhod T.I. Formation of a healthy lifestyle for young people. Proceedings of the international scientific-practical conference. Kirovograd. 2007; 180-200

7. Sergeta I.V., Dunets I.L., Stoyan N.V., Alexandrova 0.Ye. Special aspects of health of students at medical higher educational institutions and the main directions of its preservation. Eastern European Journal of Public Health. 2011; 1: 94-125.

8. Shubochkina E.I, Molchanova S.S, Kulikova A.V. Lifestyle and its significance in the formation of the health of adolescents. Materials of the International Congress. Health, education, upbringing of children and youth in the XXI century. Moscow. 2004; 271-324.

9. Voloshko N.I. Psychology of the formation of a healthy lifestyle in the educational process. The scientific world. 2012; 3: 26-39.

Work is executed within the framework of doctoral dissertation "Scientific bases of complex hygienical estimation of quality of life and adaptation possibilities of student's and student young people that is in the conditions of modern establishments of formation of different types»

\section{ORCID and contributionship:}

Oksana V. Tymoshchuk: 0000-0001-9179-9951 A,D,F

Oksana Y. Zhurakivska: 0000-0002-1041-4237 B,D

Volodymyr V. Derpak: 0000-0002-5025-7184 ${ }^{B, C}$

Iryna O. Kostitska: 0000-0003-4319-0986 C,F

Iryna T. Tokar: 0000-0002-8411-5045 E,F

\section{Conflict of interest:}

The Authors declare no conflict of interest.

\section{CORRESPONDING AUTHOR \\ Oksana V. Tymoshchuk}

3b Amatorskaya street 76493, Ivano-Frankivsk, Ukraine

tel: +380991633529

e-mail: oksanavorob4ak@gmail.com

Received: 21.10 .2019

Accepted: 19.05 .2020

A - Work concept and design, B - Data collection and analysis, C - Responsibility for statistical analysis,

D-Writing the article, $\mathbf{E}$-Critical review, $\mathbf{F}-$ Final approval of the article 